\title{
Neural Differentiation of Bone Marrow-Derived Mesenchymal Stem Cells: Applicability for Inner Ear Therapy
}

\author{
Jae-Hong Lee ${ }^{1 *}$, Won Kyung Kang ${ }^{2 *}$, Jae-Hyun Seo ${ }^{1}$, Mi-Yung Choi ${ }^{1}$, \\ Yang Hyun Lee ${ }^{1}$, Hyo Min Kim¹ and Kyoung-Ho Park ${ }^{1}$ \\ ${ }^{1}$ Departments of Otolaryngology-HNS, ${ }^{2}$ Surgery, The Catholic University of Korea College of Medicine, Seoul, Korea
}

Background and Objectives: Regeneration or replacement of damaged hair cells and neurons in the cochlea might be an ideal treatment for sensorineural hearing loss (SNHL). The purpose of the present study was to investigate whether mesenchymal stem cells (MSCs), derived from the bone marrow of rats, could differentiate into auditory hair cells and neurons. Materials and Methods: The centrifuge gradient method was used to isolate MSCs from the bone marrow of rats. To confirm whether bone marrow-derived MSCs can differentiate into neuronal cells, culture medium with glial cell-derived neurotrophic factor, brain-derived neurotrophic factor and neurotrophin-3 for 14 days. In addition, immunofluorescence staining and RT-PCR were performed for characterization of the neurospheres and differentiated cells from 7 and 14 day cultures. Results: The results showed that MSCs could differentiate into neuron-positive and hair cell-positive cells, using different compositions of growth factors. And RT-PCR result was identified high or low of gene expression all these differentiated cells. Conclusions: Rat bone marrow-derived MSCs differentiated into neuronal progenitor cells. These cells might be useful for the treatment of SNHL.

Korean J Audiol 2012;16:47-53

\section{Introduction}

Hearing loss is one of the most common disabilities found worldwide; the severity can range from modest difficulty with speech comprehension to profound deafness. In over $80 \%$ of cases, the cause of hearing loss is related to the degeneration and death of auditory hair cells and their associated spiral ganglion neurons. ${ }^{1)}$ The damaged hair cells and spiral ganglion cells have a limited capacity for self-repair. ${ }^{2)}$

The bone marrow contains two types of stem cell populations, the hematopoietic stem cells (HSCs) and mesenchymal stem cells (MSCs). HSCs are the source of blood cells; the MSCs have the capacity for self-renewal. MSCs have the ability to differentiate into stromal cells including muscle, epithelium, and neural cells. ${ }^{3-8)}$ The ability of MSCs to divide (self-renewal) and differentiate (plasticity) suggests that they might be useful for cell repair.

Regeneration or replacement of damaged hair cells and neurons in the cochlea might provide ideal treatment for sensorineural hearing loss (SNHL). Recent studies have demonstrat- ed that auditory hair cells and neurons can differentiate from endogenous stem cells of the inner ear and from embryonic stem cells. ${ }^{9,10)}$ Therefore, bone marrow-derived MSCs might be used to treat irreversible inner ear disease, especially SNHL.

The purpose of the present study was to investigate whether MSCs derived from the bone marrow of rats could differentiate into auditory hair cells and neurons.

\section{Materials and Methods}

Animals

The Animal Ethics Committee, at the Medical College of the Catholic University of Korea, approved all experimental protocols (CUMC 2008-0115-02). A total of 10 Sprague-Dawley $(\mathrm{SD})$ rats were used in this study.

The isolation and culture of mesenchymal stem cells from bone marrow

Ten SD rats were anesthetized with an intraperitoneal injection of sodium pentobarbital $(4 \mathrm{mg} / 100 \mathrm{~g})$. A small skin inci- 
sion was made to expose the femur and tibia. Approximately $2-3 \mathrm{~mL}$ of bone marrow cells were aspirated and mixed with an equal volume of phosphate buffered saline (PBS) with hep$\operatorname{arin}(10$ units $/ \mathrm{mL})$. The cells were then centrifuged at $1000 \mathrm{rpm}$ for 10 minutes. The cell pellets were resuspended with bone marrow-derived mesenchymal stem cells (BM-MSCs) medium composed of Dulbecco's Modified Eagle Medium (Gibco, Carlsbad, CA, USA) supplemented with 10\% fetal bovine serum (FBS; Biowest, Nuaille, France), 100 units/mL penicillinstreptomycin (Gibco, Carlsbad, CA, USA), and $0.1 \mathrm{mg} / \mathrm{mL}$ of streptomycin (Gibco, Carlsbad, CA, USA). Five days after culture, the suspension was discarded. Only the cells that attached to the culture dish were isolated and rinsed. These cells were then cultured in minimum essential media alpha $(+)$ glucose, (Gibco, Carlsbad, CA, USA) containing 10\% FBS and 1\% P/ $\mathrm{S}$. The culture medium was replaced at 3-day intervals. Only MSCs that were subcultured to the third generation were used for the experiments (Fig. 1A).

\section{Differentiation of bone marrow-derived mesenchymal stem cells into neuronal progenitor cells, hair cells and neurons}

Bone marrow-derived MSCs were isolated by density gradient centrifugation and sub-cultured three times. The BMMSCs were cultured separately and aliquots of the cells were transferred into a 4 well chamber slide (Nalgen Nunc International, Rochester, NY, USA) at a concentration of $1 \times 10^{4}$ cells/ well. Variable concentrations of growth factors were added to the culture medium and the differentiation into neuronal progenitor cells, hair cells and neurons was induced. All these neural differentiation medium changes were replaced at 3-day intervals.

\section{The differentiation into neurospheres}

To determine whether the bone marrow-derived MSCs could differentiate into neurospheres, the MSCs were cultured in a medium containing $20 \mathrm{ng} / \mathrm{mL}$ of epidermal growth factor (E$\mathrm{GF}$, invitrogen) and $10 \mathrm{ng} / \mathrm{mL}$ of basic fibroblast growth factor (bFGF, invitrogen) for 14 days. At 3-day intervals, $10 \mathrm{ng} /$ $\mathrm{mL}$ of bFGF was added to the culture medium three times (Table 1).

\section{The differentiation into hair cells and neurons}

The differentiation into hair cells and neurons was induced by altering the composition of the culture medium used for the BM-MSCs. The basic medium was a neurobasal medium. The nerve growth factors added included glial-derived neurotrophic factor (GDNF, invitrogen), brain-derived neurotrophic factor (BDNF, invitrogen) and neurotrophin-3 (NT-3, invitrogen)
Table 1. Neurosphere and neuron medium conditions

\begin{tabular}{ll}
\hline $\begin{array}{c}\text { Neurosphere medium } \\
\text { (total volume } 50 \mathrm{~mL})\end{array}$ & \multicolumn{1}{c}{$\begin{array}{c}\text { Neuron medium } \\
\text { (total volume } 50 \mathrm{~mL})\end{array}$} \\
\hline DMEM : F12 $(1: 1)$ & Neurobasal Medium \\
B-27 supplement $1 \mathrm{~mL}$ & B-27 supplement $1 \mathrm{~mL}$ \\
L-Glutamine $2 \mathrm{mM}$ & L-Glutamine $2 \mathrm{mM}$ \\
EGF $10 \mathrm{ng} / \mathrm{mL}$ & GDNF $10 \mathrm{ng} / \mathrm{mL}$ \\
bFGF $20 \mathrm{ng} / \mathrm{mL}$ & BDNF $10 \mathrm{ng} / \mathrm{mL}$ \\
Penicillin-Streptomycin & NT-3 $10 \mathrm{ng} / \mathrm{mL}$ \\
& Penicillin-streptomycin \\
\hline
\end{tabular}

DMEM: Dulbecco's Modified Eagle Medium, EGF: epidermal growth factor, bFGF: basic fibroblast growth factor, GDNF: glial cell-derived neurotrophic factor, BDNF: brain-derived neurotrophic factor, NT-3: neurotrophin-3

(Table 1).

\section{Confirmation of the presence of the hair cells and neurons using immunocytochemistry}

Bone marrow-derived MSCs were differentially cultured; aliquots of the cells were transferred into a Lab-Tec 4-well Chamber Slide (Nalgene Nunc International, Rochester, NY, USA) at a concentration of $1 \times 10^{4}$ cells/well. Then, the differentiation into hair cells and neurons was induced. Then immunocytochemistry was performed 14 days after cells differentiation. First, to confirm specific cellular proliferation, BrdU (5-Bromo-2'-deoxy-uridine Labeling and Detection Kit, Roche, Indianapolis, IN, USA), a marker for cellular proliferation was used; BrdU labeling was performed over 24 hours. The washing buffer was PBS containing 3\% Bovine Serum Albumin (BSA, Ogilvie ST Essendon, Australia). The labeled cells were rinsed three times. Thereafter, fixation was performed using 4\% paraformaldehyde for 15 minutes. To permeate, the samples were treated with $0.5 \%$ Triton X-100 (Promega Corporation, Madison, WI, USA) at room temperature for $20 \mathrm{mi}$ nutes. The samples were treated with primary antibody, antiBrdU working solution (1:10), overnight, and then rinsed three times with PBS containing 3\% BSA.

Next, the samples were treated with a secondary antibody, anti-mouse-Ig-Fluorescein working solution ( $1: 200)$, at room temperature for a few hours. Following this, blocking was performed with 5\% normal goat serum. In each sample, specific cellular markers were used; glial cell markers such as Glial Fibrillary Acidic Protein (GFAP, Abcam, Cambridge, UK) and S-100 (Abcam), neuronal cell markers such as BIII-tubulin (Abcam) and NeuN (Abcam), neuronal progenitor markers such as nestin (Abcam), and hair cell markers such as myosin VIIA (Abcam).

A double staining procedure was performed. All of the antibodies that underwent double staining were processed overnight and then rinsed three times with PBS containing 3\% B- 


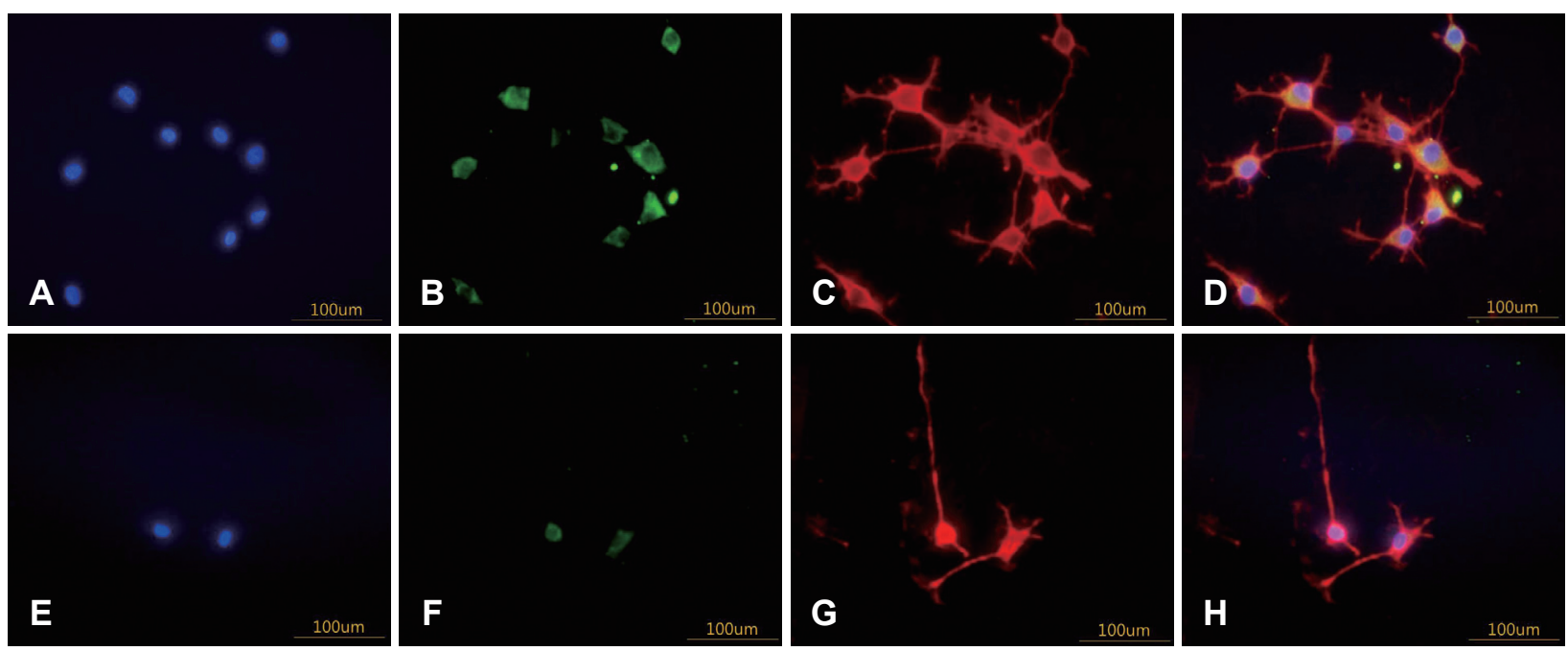

Fig. 1. Double-labeled immunochytochemistry of neural progenitor marker and hair cell markers (blue) nuclei counterstained with DAPI; (green) stained with BrdU; (red) stained with nestin (A-D), and Myosin VIla (E-H). (D, H) Merged images ( $\times 400, n=5, b a r s=100 \mu m)$.

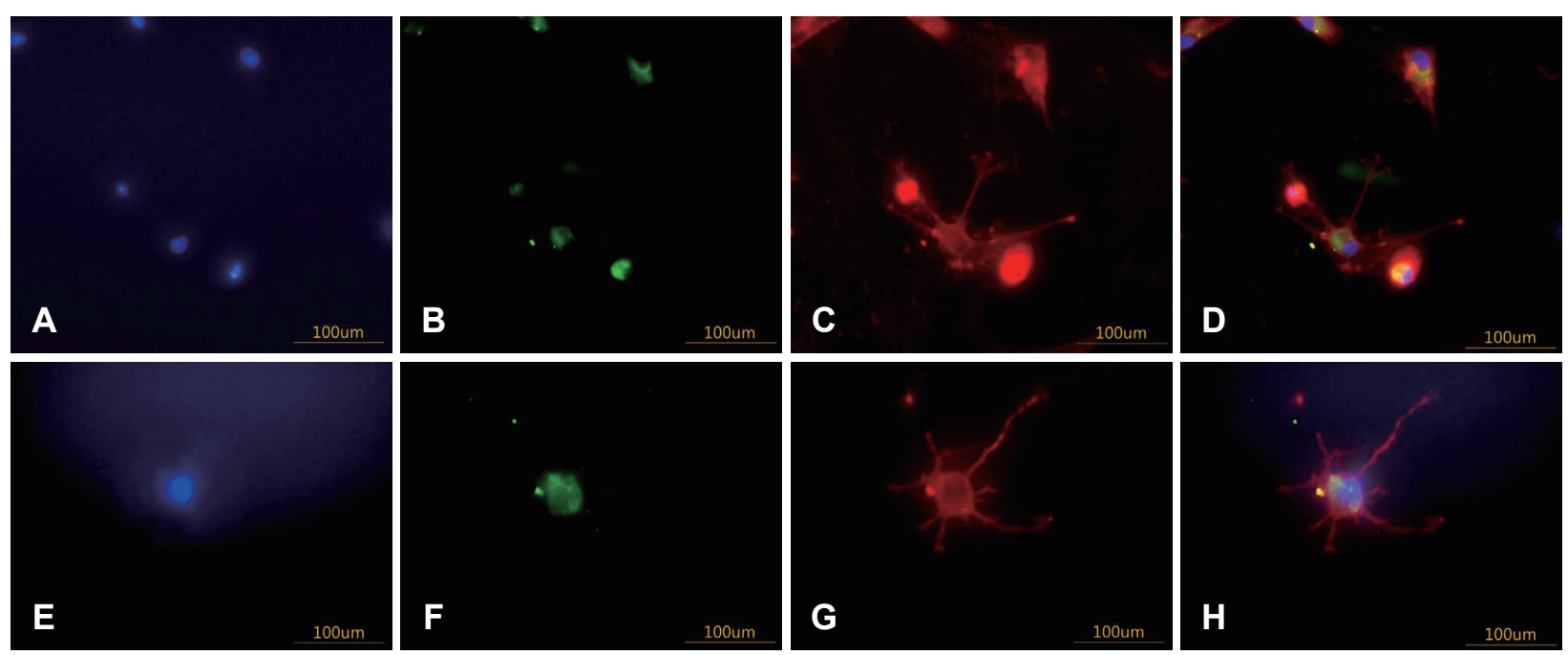

Fig. 2. Double-labeled immunochytochemistry of Schwann cell markers (blue) nuclei counterstained with DAPI; (green) stained with BrdU; (red) stained with s100 protein (A-D), and GFAP (E-H). (D, H) Merged images ( $\times 400, n=3$, bars=100 $\mu \mathrm{m})$.

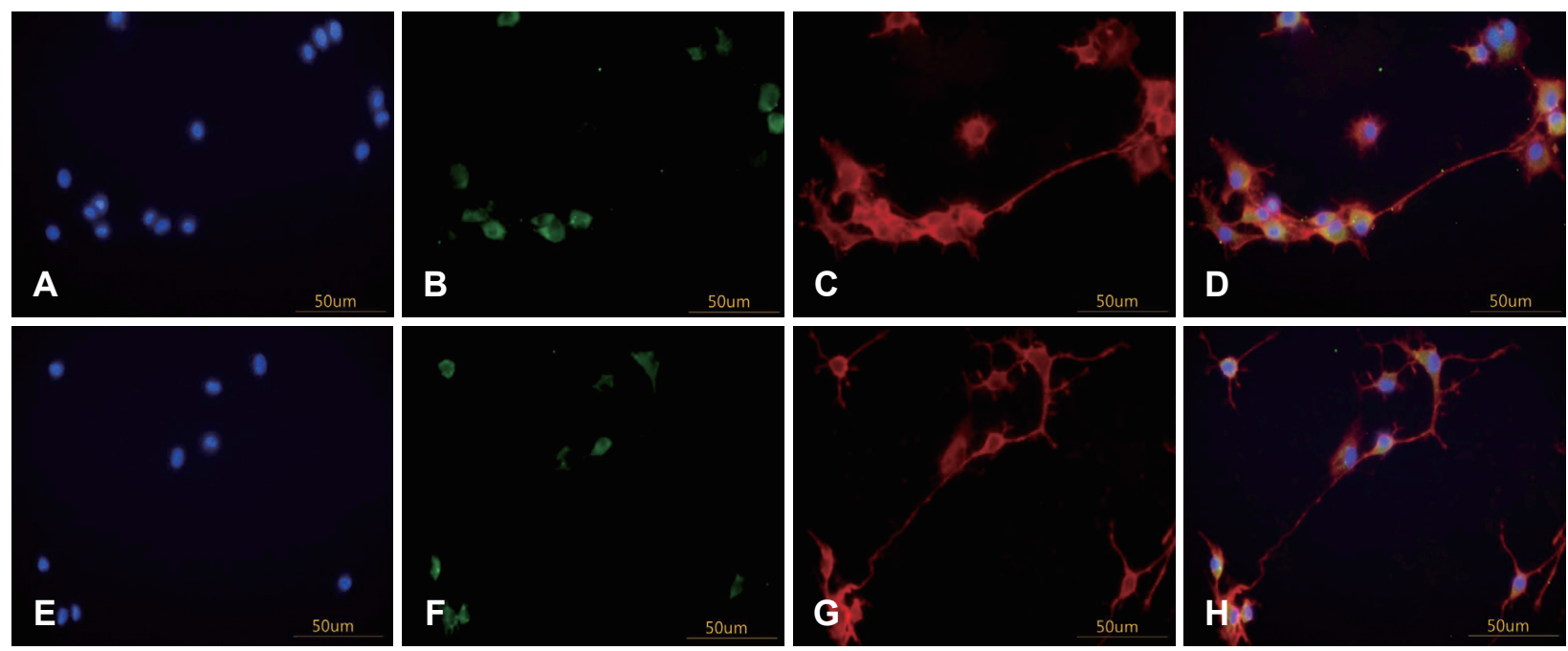

Fig. 3. Double-labeled immunochytochemistry of Neuron markers (blue) nuclei counterstained with DAPI; (green) stained with BrdU; (red) stained with $\beta$ III-tubulin (A-D), and NeuN (E-H). (D, H) Merged images $(\times 200, n=5$, bars=50 $\mu \mathrm{m})$. 
SA. The secondary antibody, Alexa 555, was added to the samples at room temperature at a ratio of $1: 200$ for $1 \mathrm{hr}$. Then, expression was confirmed. In addition to the nuclear staining, the cells were mounted with DAPI (4',6-diamidino-2-phenylindole)-conjugated mounting medium (Vectashild, Burlingame, CA, USA). Expression was confirmed using a Fluorescence Attached Microscope (Olympus corporation, Shinjuku, Tokyo, Japan). Based on the evaluation of cells, the number of expressed cells per total num-ber of cells was calculated.

\section{The expression of hair cells and neuronpositive cells on RT-PCR}

The bone marrow-derived-MSCs were sub-cultured three times in a $100 \mathrm{~mm}$ dish at a concentration of $1 \times 10^{4}$ cells/well. Then, differentiation into hair cells and neurons was induced. The cells were studied to determine whether they differentiated into neuronal progenitor cells, hair cells and neurons over time. The cells were divided into two groups: 7-day and 14- day differentiation. RNA was extracted from these cells and PCR performed by reverse transcription.

RNA was isolated from the cultured cells, using the AXYGEN RNA mini prep kit (Axygen Scientific, Inc., Union City, CA, USA). The isolated RNA was used for the reverse transcription at $42^{\circ} \mathrm{C}$ for 60 minutes and at $95^{\circ} \mathrm{C}$ for 5 minutes with the RT Premix Kit (Intron Biotechnology, Seongnam, Korea). Then, cDNA was synthesized. The synthesized cDNA was quantified to $100 \mathrm{ng}$. Then, using the RT-PCR premix (Bioneer, Daejeon, Korea) and GFAP, S100, BIII-tubulin, nestin, Bone Morphology Protein 4 (BMP4), BMP7, myosin VIIA primer, DNA denaturation was performed at $94^{\circ} \mathrm{C}$ for $5 \mathrm{~min}-$ utes. Each of the gene annealing temperatures required different conditions; the reaction was performed for 30 seconds. At $72^{\circ} \mathrm{C}$, DNA polymerization and extension were performed for 5 minutes. The House keeping gene, GlycerAldehyde-3-Phosphate Dehydrogenase was used as a control. Expression was confirmed by electrophoresis, using a $2 \%$ agarose gel. The ex-

Table 2. PCR conditions of RT-PCR

\begin{tabular}{|c|c|c|c|c|}
\hline Gene name & & Sequence (5'-3') & Annealing temp $\left({ }^{\circ} \mathrm{C}\right)$ & Size (bp) \\
\hline \multirow[t]{2}{*}{ GAPDH } & $\mathrm{F}$ & ctactggcgctgcaaaggctgt & 54 & 357 \\
\hline & $R$ & gccatgaggtccaccaccctg† & & \\
\hline \multirow[t]{2}{*}{ Nestin } & $\mathrm{F}$ & aacaggaccaagagacattg & 56 & 211 \\
\hline & $R$ & tttactgcctctacgetctc & & \\
\hline \multirow[t]{2}{*}{$S 100$} & $\mathrm{~F}$ & ctttaaatgcgttcctcatc & 51 & 156 \\
\hline & $R$ & ttctgatggagttgcttttt & & \\
\hline \multirow[t]{2}{*}{ GFAP } & $\mathrm{F}$ & tttctaaaggcctcttcctt & 56 & 192 \\
\hline & $R$ & ctgggtacattttgtgtgtg & & \\
\hline \multirow[t]{2}{*}{ BMP4 } & $\mathrm{F}$ & agtgaaaactctgcttttcg & 53 & 217 \\
\hline & $R$ & ccagtctcgtgtccagtagt & & \\
\hline \multirow[t]{2}{*}{ NF } & $\mathrm{F}$ & caaagaagaggggaagccac & 55 & 258 \\
\hline & $R$ & tttcatctgctgggctcaag & & \\
\hline \multirow[t]{2}{*}{$\beta I I I-T u b u l i n$} & $\mathrm{~F}$ & aagttttggagagggaaatc & 54.5 & 188 \\
\hline & $R$ & agggaggtagagttggaaag & & \\
\hline \multirow[t]{2}{*}{ Myosin VIIA } & $\mathrm{F}$ & tacatcgacatccacttcaa & 54.5 & 154 \\
\hline & $R$ & tctgatcctcactcataccc & & \\
\hline
\end{tabular}

GAPDH: GlycerAldehyde-3-Phosphate Dehydrogenase, GFAP: Glial Fibrillary Acidic Proten, BMP4: Bone Morphology Protein 4
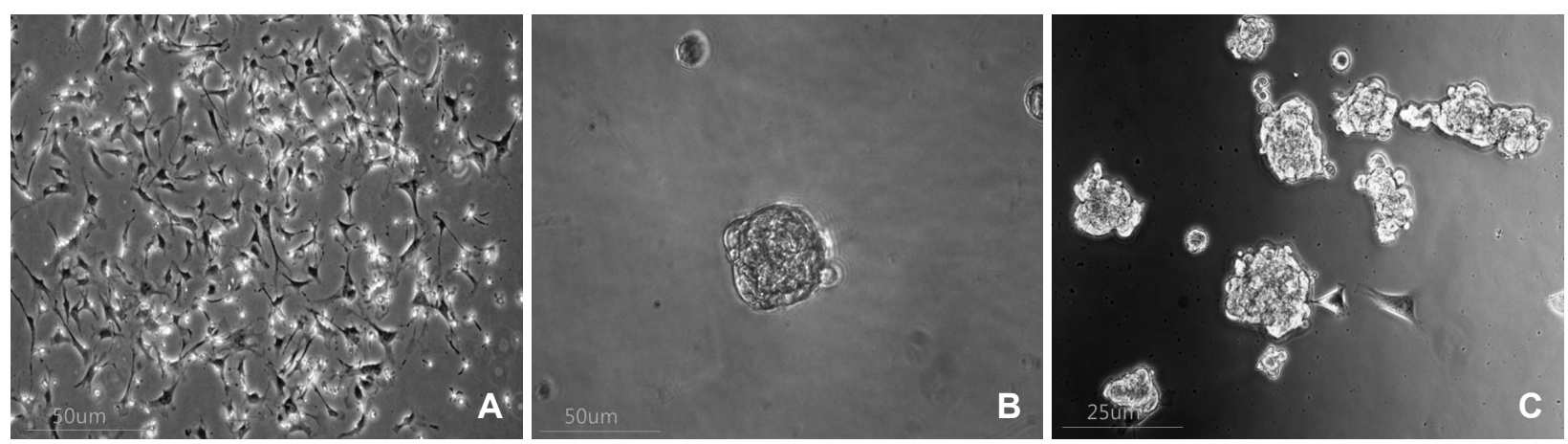

Fig. 4. Bone marrow-derived MSCs of primary culture (A). MSCs were differentiated into neurosphere after 7 days (B). Neurosphere medium differentiated about 10 days after. $(A)$ and $(B)$ are shown at 200 magnification. $(C)$ is shown at 100 magnification $(n=5$, bar=100 $\mu$ m). MSCs: mesenchymal stem cells. 
pressed genes were confirmed by band analysis using the Image Analysis System (Bio-Rad, Herculesus, CA, USA). The primer compositions for each gene are listed in Table 2.

\section{Results}

\section{Confirmation of differentiation of hair cells and neurons using immunocytochemistry}

For differentiation into neuronal positive cells the isolated MSCs were cultured in medium containing BDNF, GDNF and NT-3. 14 days after, spherical-shaped cells were observed (Fig. 1-3). To confirm whether the cells were neuron, hair cell or schwann cell, the cells were treated with specific neural lineage markers. The expression of neuronal precursor cell markers (nestin) and cellular proliferation markers (BrdU) in the neuronal positive cells were confirmed by immunocytochemistry (Fig. 1A-D). These cells had the capacity for subculture and self-renewal. The sphere cells (Fig. 4A) became spherical after 1 week. After 2 and 3 weeks, the cells were larger (Fig. $4 \mathrm{~B}, \mathrm{C}$ ), and the sphere measured 50-150 $\mu \mathrm{m}$. Subsequently, the size of the neuronal progenitor cells did not increase further.

Neuronal positive cells expressed $\beta$ III-tubulin (Fig. 3A-D) and NeuN (Fig. 3E-H), as a markers for neurons. Moreover, S-100, a marker for glial cells (Fig. 2A-D), was also observed. And the hair cells markers myosin VIIA positive cells were seen in approximately $3-4 \%(400 \pm 100)$ of $1 \times 10^{4}$ cells in the neuronal medium (Fig. 1E-H).

Neurons are characterized by the presence of axons and den- drites, which were observed after culture (Fig. 3). Although the number of cells did not increase, axon-like and dendrite-like cells were developed neuronal differentiation (Fig. 2, 3). The neuron-like cells stained for BrdU (Fig. 3B, F), and all of the cells expressed specific markers for neurons, such as, NeuN and $\beta$ III-tubulin (Fig. 3). Overall, $7-8 \%(700 \pm 100)$ of $1 \times 10^{4}$ cells in neuronal medium expressed the neuronal cell markers. Also another cell group also stained for BrdU (Fig. 1B, F) and expressed neuronal progenitor cell markers, such as nestin, and glial cell markers, such as S100 and GFAP (Fig. 1, 2). These cells morphology were more elongated. And GFAP and s100 positive cells were seen in approximately about $20 \%$ (2000 \pm 50 ) of $1 \times 10^{4}$ cells in the neuronal medium expressed.

\section{Confirmation of differentiation of neuronal cells using \\ RT-PCR}

In 14-day cultures, the differentiation from BM-MSCs to neurospheres and neurons were confirmed based on the expression of genes such as: nestin, BMP4, GFAP, S-100, NF, and $\beta I I I-$ tubulin (Fig. 5). However, the expression of Myosin VIIa (a hair cell marker) was extremely low, until two weeks. The proportion of cells that differentiated into Schwann cells and neurons was much higher than cells that differentiated into hair cells.

\section{Discussion}

The stem cells located in the bone marrow are the primary source of blood cells. In addition to these hematopoietic stem
Fig. 5. RT PCR analyses of gene expression of specific markers. GAPDH: GlycerAldehyde-3-Phosphate Dehydrogenase, GFAP: Glial Fibrillary Acidic Proten, BMP4: Bone Morphology Protein 4.

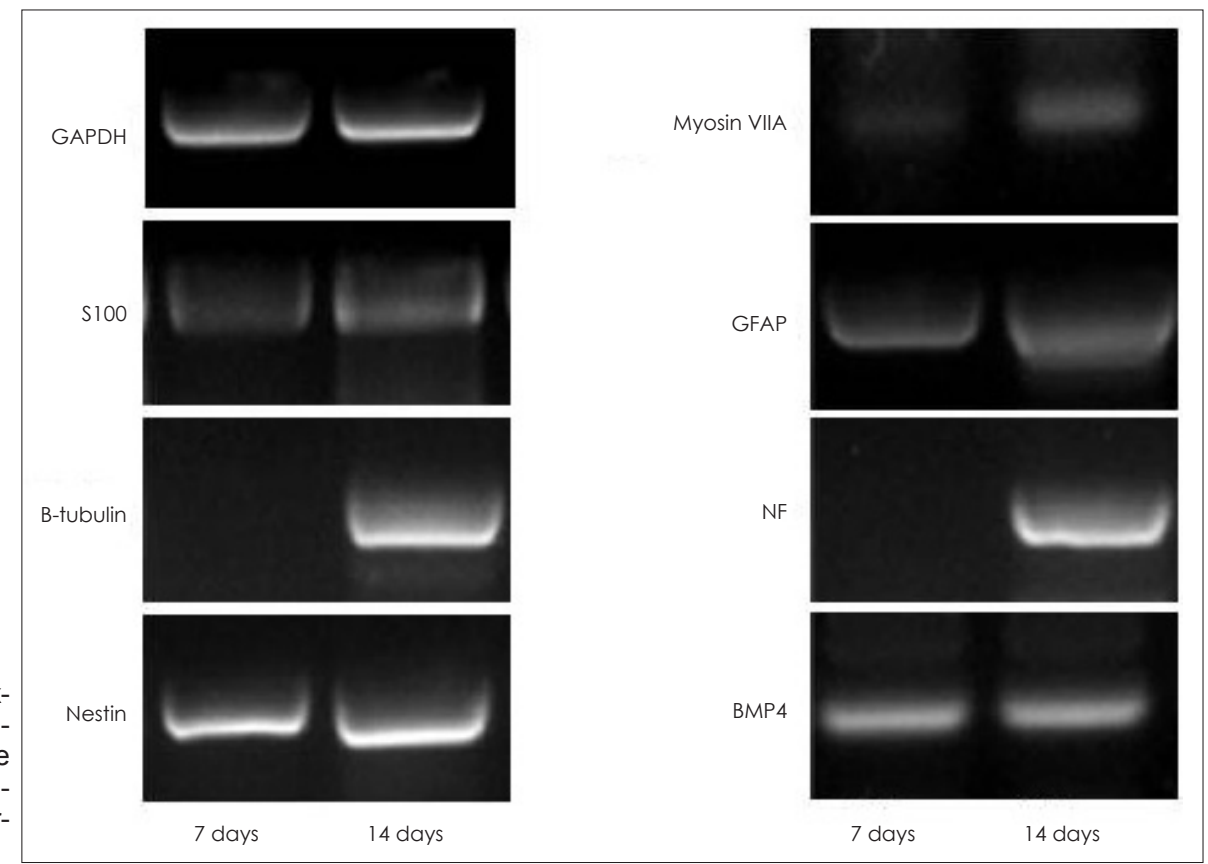


cells, the bone marrow contains MSCs that can differentiate into various cell types including all three embryonic germ layers. Recent studies have demonstrated that bone marrow-derived MSCs can differentiate into cartilage, insulin-producing cells, muscle cells, and neurons. ${ }^{3-8)}$ Furthermore, bone marrowderived MSCs have been reported to differentiate into inner ear sensory cells. ${ }^{11)}$ The results of this study show that bone marrow-derived MSCs, from the rat, can differentiate into neuronal progenitor cells, and be used for the treatment of injured cells.

Although there are several methods for the isolation of stromal cells from bone marrow, there is currently no optimal method. The known methods include plastic adherence, ${ }^{12)}$ gradient density centrifugation ${ }^{13)}$ and immunomagnetic selection. ${ }^{14,15)}$ In this study, the MSCs were isolated and cultured from bone marrow using the gradient density centrifugation method.

Jeon, et al. ${ }^{11)}$ reported that MSCs from bone marrow could differentiate into inner ear sensory cells. These authors noted that over-expression of the pro-sensory transcription factor, Math1, in sensory epithelial precursor cells, induced the expression of developing sensory epithelial markers and mature hair cell markers; in addition, they detected the expression of supporting cell markers. ${ }^{11)}$ In the current study, bone marrowderived MSCs were isolated and cultured in neurosphere medium containing bFGF and EGF, and as a result, neurospheres developed. EGF and bFGF are known to play a role in promoting the proliferation and differentiation of neurons. ${ }^{16,17)}$ The neurospheres identified in this study expressed nestin and BrdU, both neural progenitor cell markers. Nestin is an intermediate filament protein expressed in dividing cells during early development in the central nervous system, peripheral nervous system and in myogenic and other tissues; it is expressed by neuronal precursor cells; however, it can also be expressed by many other types of cells during development. ${ }^{18)}$ BrdU, a thymidine analog that incorporates the DNA of dividing cells during the S-phase of the cell cycle, is a marker for neurogenesis. ${ }^{19)}$

The differentiation of induced neuronal progenitor cells from mature hair cells and neurons was induced by neurotrophins including BDNF, GDNF and NT-3. BDNF is a neurotrophin that is present most abundantly in the brain. It promotes the growth of neurons and regulates the synthesis, metabolism and excretion of neuro-transmitters and the activation of neurons. BDNF and NT-3 play an important role in the maturation of inner ear neurons, and in the differentiation of neural stem cells to neurons. ${ }^{20,21)}$ GDNF and NT-3 are also known to promote the growth of glial cells, astrocytes and neurons. Incubation with these neurotrophic factors resulted in enrichment of progenitors that could be converted to hair cells and neurons.

When the bone marrow-derived MSCs were cultured using neurosphere medium and neuronal medium, the pattern of expression of specific genes was confirmed. Both the differentiation into neuronal progenitor cells and into hair cells and neurons confirmed the presence of gene expression over time. However, there was a difference in the differentiation observed in the neurosphere medium compared to the neuronal medium. The results of this study confirmed the expression of specific types of genes.

Staining properties were identified using BrdU, one of the specific markers of cell proliferation potential. However, the results confirmed the proliferation potential of neuronal progenitor cells. Bone marrow-derived MSCs, present in the neuronal medium, showed complete differentiation with cell proliferation. Compared to the neuronal progenitor cells, BrdU, a specific marker for proliferation potential, showed a relatively low degree of staining in the differentiated cells. These results suggest an inverse proportional relationship; the differentiated cells showed a lower degree of proliferation potential.

\section{Conclusion}

The results of this study demonstrated that bone marrowderived MSCs could differentiate into neuronal progenitor cells. These findings suggest the possibility that such cells might be used for further differentiation and treatment of inner ear disease, such as SNHL, on the cellular level.

\section{Acknowledgments}

This research was supported by the Yuhan Pharmapeuticals Research Fund, Seoul St. Mary's Clinical Medicine Research Program year of 2009 through the Catholic University of Korea, the Catholic Institute of Cell Therapy Basic Science Programs Foundation for the program year 2009 and the Research Fund of Catholic University ENT Alumni.

\section{REFERENCES}

1) Holley MC. Application of new biological approaches to stimulate sensory repair and protection. Br Med Bull 2002;63:157-69.

2) Warchol ME, Lambert PR, Goldstein BJ, Forge A, Corwin JT. Regenerative proliferation in inner ear sensory epithelia from adult guinea pigs and humans. Science 1993;259:1619-22.

3) Colter DC, Class R, DiGirolamo CM, Prockop DJ. Rapid expansion of recycling stem cells in cultures of plastic-adherent cells from human bone marrow. Proc Natl Acad Sci U S A 2000;97:3213-8.

4) Doyonnas R, LaBarge MA, Sacco A, Charlton C, Blau HM. Hematopoietic contribution to skeletal muscle regeneration by myelomonocytic precursors. Proc Natl Acad Sci U S A 2004;101:13507-12.

5) Herzog EL, Chai L, Krause DS. Plasticity of marrow-derived stem cells. Blood 2003;102:3483-93.

6) Hess D, Li L, Martin M, Sakano S, Hill D, Strutt B, et al. Bone marrow-derived stem cells initiate pancreatic regeneration. Nat Biotechnol 2003;21:763-70. 
7) Jiang Y, Jahagirdar BN, Reinhardt RL, Schwartz RE, Keene CD, Ortiz-Gonzalez XR, et al. Pluripotency of mesenchymal stem cells derived from adult marrow. Nature 2002;418:41-9.

8) Pittenger MF, Mackay AM, Beck SC, Jaiswal RK, Douglas R, Mosca JD, et al. Multilineage potential of adult human mesenchymal stem cells. Science 1999;284:143-7.

9) Li H, Liu H, Heller S. Pluripotent stem cells from the adult mouse inner ear. Nat Med 2003;9:1293-9.

10) Li H, Roblin G, Liu H, Heller S. Generation of hair cells by stepwise differentiation of embryonic stem cells. Proc Natl Acad Sci U S A 2003; 100:13495-500.

11) Jeon SJ, Oshima K, Heller S, Edge AS. Bone marrow mesenchymal stem cells are progenitors in vitro for inner ear hair cells. Mol Cell Neurosci 2007;34:59-68.

12) Dexter TM, Testa NG, Allen TD, Rutherford T, Scolnick E. Molecular and cell biologic aspects of erythropoiesis in long-term bone marrow cultures. Blood 1981;58:699-707.

13) Chen ZZ, Van Bockstaele DR, Buyssens N, Hendrics D, De Meester I, Vanhoof G, et al. Stromal populations and fibrosis in human longterm bone marrow cultures. Leukemia 1991;5:772-81.

14) Dezawa M, Kanno H, Hoshino M, Cho H, Matsumoto N, Itokazu Y, et al. Specific induction of neuronal cells from bone marrow stromal cells and application for autologous transplantation. J Clin Invest
2004;113:1701-10.

15) Jia L, Young MF, Powell J, Yang L, Ho NC, Hotchkiss R, et al. Gene expression profile of human bone marrow stromal cells: high-throughput expressed sequence tag sequencing analysis. Genomics 2002;79:7-17.

16) Zheng JL, Helbig C, Gao WQ. Induction of cell proliferation by fibroblast and insulin-like growth factors in pure rat inner ear epithelial cell cultures. J Neurosci 1997;17:216-26.

17) Pauley S, Wright TJ, Pirvola U, Ornitz D, Beisel K, Fritzsch B. Expression and function of FGF10 in mammalian inner ear development. Dev Dyn 2003;227:203-15.

18) Michalczyk K, Ziman M. Nestin structure and predicted function in cellular cytoskeletal organisation. Histol Histopathol 2005;20:66571.

19) Taupin P. BrdU immunohistochemistry for studying adult neurogenesis: paradigms, pitfalls, limitations, and validation. Brain Res Rev 2007;53:198-214.

20) Pirvola U, Ylikoski J. Neurotrophic factors during inner ear development. Curr Top Dev Biol 2003;57:207-23.

21) Ito H, Nakajima A, Nomoto H, Furukawa S. Neurotrophins facilitate neuronal differentiation of cultured neural stem cells via induction of mRNA expression of basic helix-loop-helix transcription factors Mash1 and Math1. J Neurosci Res 2003;71:648-58. 